\title{
Forced and internal modes of variability of the East Asian summer monsoon
}

\author{
J. Liu ${ }^{1}$, B. Wang ${ }^{2,3}$, and J. Yang ${ }^{4}$ \\ ${ }^{1}$ State Key Laboratory of Lake Science and Environment, NIGLAS, Nanjing, 210008, China \\ ${ }^{2}$ Department of Meteorology and IPRC, University of Hawaii at Manoa, Honolulu, HI 96822, USA \\ ${ }^{3}$ Guest Professor, CPEO, Ocean University of China, Qingdao 266100, China \\ ${ }^{4}$ State Key Laboratory of Earth Surface Processes and Resource Ecology, Beijing Normal University, Beijing 100875, China
}

Received: 3 April 2008 - Published in Clim. Past Discuss.: 28 May 2008

Revised: 1 September 2008 - Accepted: 22 September 2008 - Published: 3 November 2008

\begin{abstract}
The modern instrumental record (1979-2006) is analyzed in an attempt to reveal the dynamical structure and origins of the major modes of interannual variability of East Asian summer monsoon (EASM) and to elucidate their fundamental differences with the major modes of seasonal variability. These differences are instrumental in understanding of the forced (say orbital) and internal (say interannual) modes of variability in EASM. We show that the leading mode of interannual variation, which accounts for about $39 \%$ of the total variance, is primarily associated with decaying phases of major El Nino, whereas the second mode, which accounts for $11.3 \%$ of the total variance, is associated with the developing phase of El Nino/La Nina. The EASM responds to ENSO in a nonlinear fashion with regard to the developing and decay phases of El Nino. The two modes are determined by El Nino/La Nina forcing and monsoon-warm ocean interaction, or essentially driven by internal feedback processes within the coupled climate system. For this internal mode, the intertropical convergence zone (ITCZ) and subtropical EASM precipitations exhibit an out-of-phase variations; further, the Meiyu in Yangtze River Valley is also out-of-phase with the precipitation in the central North China.

In contrast, the annual cycle forced by the solar radiation shows an in-phase variation between the ITCZ and the subtropical EASM precipitation. Further, the seasonal march of precipitation displays a continental-scale northward advance of a southwest-northeastward tilted rainband from mid-May toward the end of July. This coherent seasonal advance between Indian and East Asian monsoons suggests that the position of the northern edge of the summer monsoon over the
\end{abstract}

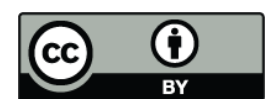

Correspondence to: J. Liu

(jianliu@niglas.ac.cn) central North China may be an adequate measure of the monsoon intensity for the forced mode. Given the fact that the annual modes share the similar external forcing with orbital variability, the difference between the annual cycle and interannual variation may help to understand the differences in the EASM variability on the orbital time scale and in the modern records.

\section{Introduction}

The East Asian summer monsoon (EASM) lies downstream the world highest Tibetan Plateau and in between the world largest Eurasian continent and the Pacific Ocean basin. This distinctive tectonic setting brings unique features to the EASM. The precise definition of the EASM domain has been ambiguous. To some the EASM is referred to as only the subtropical region between $20^{\circ} \mathrm{N}$ and $40^{\circ} \mathrm{N}$ and from $100^{\circ} \mathrm{E}$ to $140^{\circ}$ E (e.g., Zhang et al., 1996). But, the South China Sea $\left(0-20^{\circ} \mathrm{N}, 110-125^{\circ} \mathrm{E}\right)$ monsoon was often regarded as a part of EASM (e.g., Ding 1992). Zhu et al. (1986) suggested that the EASM system is composed of both tropical and subtropical systems.

Figure 1a highlights the generally recognized EASM system, which consists of East Asian (EA) subtropical front (a major rain-bearing system in the subtropics and midlatitude), the western North Pacific (WNP) Subtropical High (SH) and the WNP monsoon trough or the WNP ITCZ. The aforementioned three components are intimately coupled (e.g., Nitta, 1987; Huang and Wu, 1989; and many others). Therefore, it is advantageous to investigate EASM variability in a broader region covering all the three circulation components, so that the relationship in precipitation between the ITCZ and EA subtropical precipitation can be elucidated.

Published by Copernicus Publications on behalf of the European Geosciences Union. 


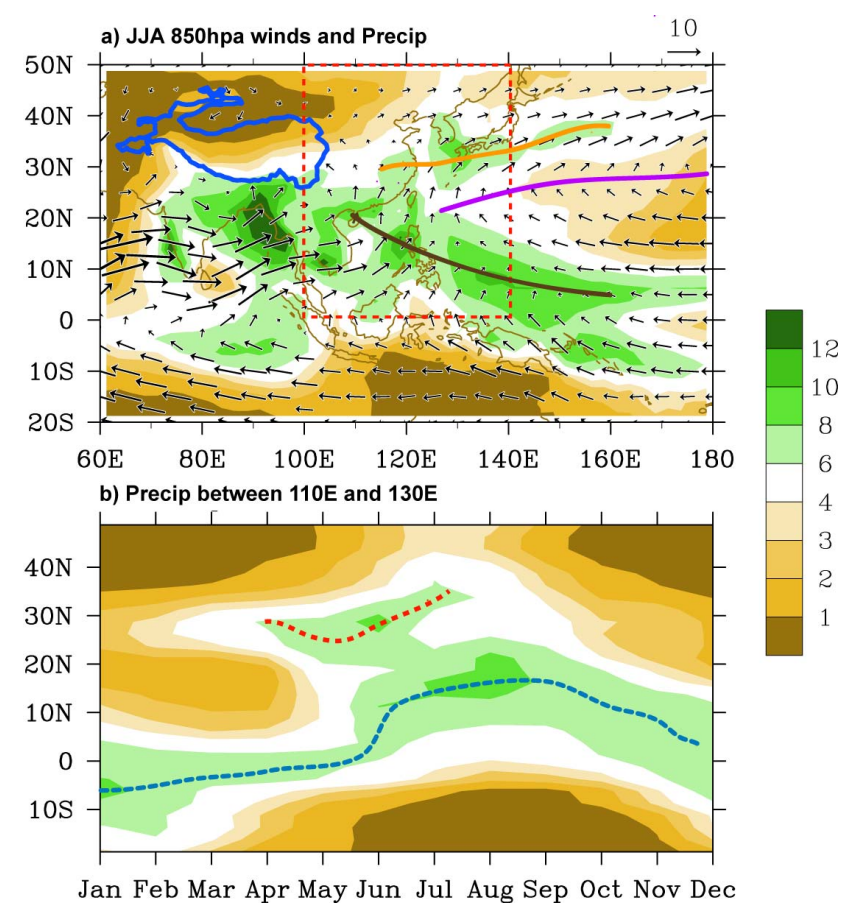

Fig. 1. (a) Climatological summer (JJA) mean precipitation (color shading in $\mathrm{mm} /$ day) and $850 \mathrm{hPa}$ winds (vectors in units of $\mathrm{m} / \mathrm{s}$ ). The Meiyu belt (brown line), WNPSH ridge (purple line) and WNP monsoon trough (dark brown line) have been outlined along with the Tibetan Plateau $3000 \mathrm{~m}$ contours (dark blue line). (b) Climatological monthly mean rainfall as a function of latitude (ordinate) and calendar month (abscissa). The precipitation is averaged over the EA sector between $110^{\circ} \mathrm{E}$ and $130^{\circ} \mathrm{E}$. The ITCZ and EASM rain belt (the subtropical frontal rain belt) have been outlined by blue and red lines, respectively. Precipitation was derived from GPCP and other variables were derived from NCEP reanalysis- 2 .

In the modern study of the EASM variations, the year-to-year variations of the EASM have often been separately studied for the subtropical region (e.g., Nitta, 1987; Huang and $\mathrm{Wu}$, 1989; Lee and Jhun, 2005; Zhou and Yu, 2005) and the tropical region (e.g., Murakami and Matsumoto, 1994; Wu and Wang, 2000). Here we focus on cohesive variability among the tropics, subtropics and mid-latitude in a broader region for the EASM $\left(0-50^{\circ} \mathrm{N}, 100-140^{\circ} \mathrm{E}\right)$.

Besides the domain, measure of the EASM intensity is another issue. The modern monsoon meteorologists refer a strong EASM as to a situation in which the southerlies deeply penetrate inland to northern China, which corresponds to an enhanced precipitation in northern China but a deficient Meiyu (Ding, 1992). On the other hand, the paleoclimate scientists use the $\delta^{18} \mathrm{O}$ at Hulu cave near Nanjing $\left(32^{\circ} \mathrm{N}\right.$, $119^{\circ} \mathrm{E}$ ) as a proxy for EASM strength as it impacts the oxygen isotope composition of stalagmite (Wang et al., 2001; Yancheva et al., 2007). Thus, a strong EASM in paleoclimate community implies abundant Meiyu, just opposite to the modern definition. To reconcile this issue, we shall contrast the behavior of the major modes of the annual and interannual variations in EASM. The former is driven by solar radiative forcing that is relevant to understand the orbital variability of the EASM, while the later is relevant to the concept of the modern monsoon variability.

Another issue motivated the present study is interpretation of EASM variability. On orbital time scales, an enhanced EASM (increased Meiyu) has been attributed to northward migration of the ITCZ (e.g., An, 2000; Ding et al., 1995, Yancheva et al., 2007). As shown in Fig. 1b, the Meiyu and ITCZ (or WNP monsoon trough) are two distinctive yet coupled systems over the region. As will be shown, the interannual variation of the EA subtropical rainfall, Meiyu or Baiu for instance, is often out of phase with ITCZ rainfall. Once again, to reconcile this dilemma in variability on the two time scales, we shall compare the annual and interannual variability, so that the different relationships between the EASM and ITCZ precipitation may be better understood.

One of the objectives of this study is to bridge the interests between the present-day monsoon and paleo-monsoon studies. Although our analysis focuses on the annual variation and interannual variation, we regard the former as representing a forced mode (or response) to external solar forcing, while the latter primarily reflects the internal mode of variability due to the feedback processes within the coupled climate system (not necessarily the local EASM system). Given the resemblance between the orbital variability and annual variation, the analysis results will facilitate understanding the differences between the orbital and interannual variability. Section 2 describes method and data. In Sect. 3 and 4, we examine the major modes of interannual variations and their origins and teleconnection. In Sect. 5 we analyze slow and fast components of the annual variation (the forced seasonal march) of the EASM. In Sect. 6 we discuss the implications of the present results in understanding the difference between the orbital variability and the interannual variability.

\section{Method and data}

Since the EASM has both characteristic rainfall distribution and associated large-scale circulation, we use MultiVariate EOF analysis (MV-EOF) to extract major modes of variability. The variables selected for MV-EOF include observed precipitation, sea-level pressure, and $850 \mathrm{hPa}$ zonal and meridional winds. The MV-EOF analysis method was described in detail in Wang (1992). The method has the advantage of capturing spatial phase relationships among various selected circulation and precipitation fields. In the MVEOF analysis, an area-weighted, normalized covariance matrix was constructed for the combined four meteorological fields. After the EOF decomposition, dimensional eigenvectors (spatial patterns) are obtained and presented.

The data used include (1) pentad and monthly precipitation data compiled by the Global Precipitation Climatology 
Project (GPCP) for the 1979-2006 period (Adler et al. 2003), (2) the wind and sea level pressure data, gridded at $2.5^{\circ} \times 2.5^{\circ}$ resolution, taken from the National Centers for Environmental Prediction/Department of Energy reanalysis (henceforth, NCEP-2; Kanamitsu et al., 2002); (3) the sea surface temperature (SST) data were obtained from the improved Extended Reconstructed SST Version 2 (ERSST V2; Smith and Reynolds, 2004). In this study, summer (June, July, and August or JJA) mean anomalies are defined by the deviation of JJA mean from the corresponding long-term (1979-2006) mean climatology. To focus on the interannual variation, we further applied Fourier harmonic analysis to the time series of JJA mean anomalous fields. All harmonics with periods longer than eight years were removed and the resultant data describe interannual variations on 2-7 year time scale.

\section{Major modes of interannual variability of the EASM}

The first two MV-EOF modes carry about $50 \%$ of the total variance. The first mode, which carries $38.6 \%$ of the total variance, is well distinguished from the rest modes at 95\% confidence level, according to the criterion proposed by North et al. (1982). The second mode accounts for $11.3 \%$ of the total variance and is not significantly distinguishes from the third mode that accounts for $7.8 \%$ of the total variance. The statistical inseparability of the second and third modes may depend on the selected sample size and they might exchange their importance in terms of their fractional variance when longer time series or different time periods are examined. Nevertheless, it does not prohibit us in seeking for their physical meanings.

The spatial pattern of the leading mode is characterized by a prominent abnormal WNPSH (Fig. 2a), which means a southwestward extension of its normal position in comparison with the climatology shown in Fig. 1a. The low-level southwesterly is considerably strengthened from the southeast China, across East China Sea to South of Japan. Accordingly, the rainfall intensifies along the EA subtropical front that stretches from the Yangtze River and Huai River valley (typical Chinese Meiyu) to South Korea (Changma) and South Japan (Baiu). Meanwhile, the tropical rainfall decreases in the WNP monsoon trough over the South China Sea and Philippine Sea in accordance with the southwestward displacement of the WNPSH. The structure of the first mode suggests an anti-correlation between the WNP ITCZ and EA subtropical frontal precipitation on the interannual time scales.

The second mode features rising pressures over the Asian continent and falling pressures over the WNP (Fig. 2b). This pressure anomaly pattern implies an overall weakening of the EASM. The WNPSH weakens and the WNP monsoon trough retreats southward. The rainfall is notably enhanced over the southern Japan and South Korea, as well as southern China. Reduced rainfall is seen in the middle and lower (a) EOF1 (38.6\%)
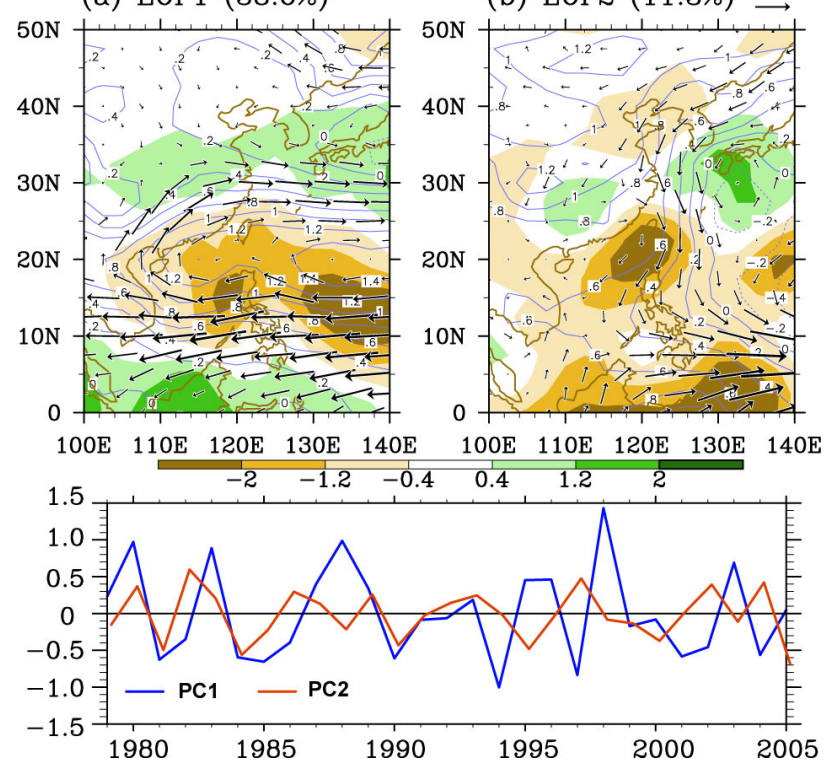

Fig. 2. Spatial patterns (upper panels) and their corresponding principle components (lower panels) of the first two MV-EOF modes of the EASM. Shown in the upper panels are anomalous JJA $850 \mathrm{hpa}$ winds (vectors in units of $\mathrm{m} / \mathrm{s}$ ), precipitation (color shading in units of $\mathrm{mm} /$ day), and sea-level pressure (contours in units of $\mathrm{hPa}$ ). Precipitation was derived from GPCP and other variables were derived from NCEP reanalysis-2.

reaches of the Yellow River Valley. Note that the EOF pattern shows an in phase variation between the WNP monsoon trough and the northern China precipitation, but the Meiyu remains anti-correlated with WNP trough precipitation.

The time evolution of the leading mode (principal component 1 or PC1 for short) shown in Fig. 2a indicates that the major peaks (1980, 1983, 1988, 1998 and 2003) primarily occur in the summers following the mature phases of El Nino events. It is interesting to note that while the peaks of the PC 1 are primarily associated with decaying El Nino, most of the major minima of the PC1 are not related to La Nina decaying years. This suggests that the response of EASM leading mode to El Nino and La Nina is nonlinear. Note also that the minimum of $\mathrm{PC} 1$ tends to occur in the developing El Nino years after 1990 (e.g., 1994, 1997, 2002 and 2004), while occur in La Nina years before 1990 (e.g., 1981, 1984 and 1985). It seems that a decadal change might have modified the EASM response to ENSO forcing. This deserves a further study with longer period of data.

The temporal evolution of the second mode (PC2) shows major maxima occurring in 1980, 1982, 1986, 1989, 1993, 1997, 2002, and 2004 (Fig. 2b). Six out of the eight listed years belong to El Nino developing years except 1980 and 1989. Further, the minima of PC2 occur in 1981, 1984, $1990,1995,2000$, and 2005. Five out of the six listed years (1981, 1984, 1995, 2000, and 2005) correspond to La Nina 
(a) EOF1
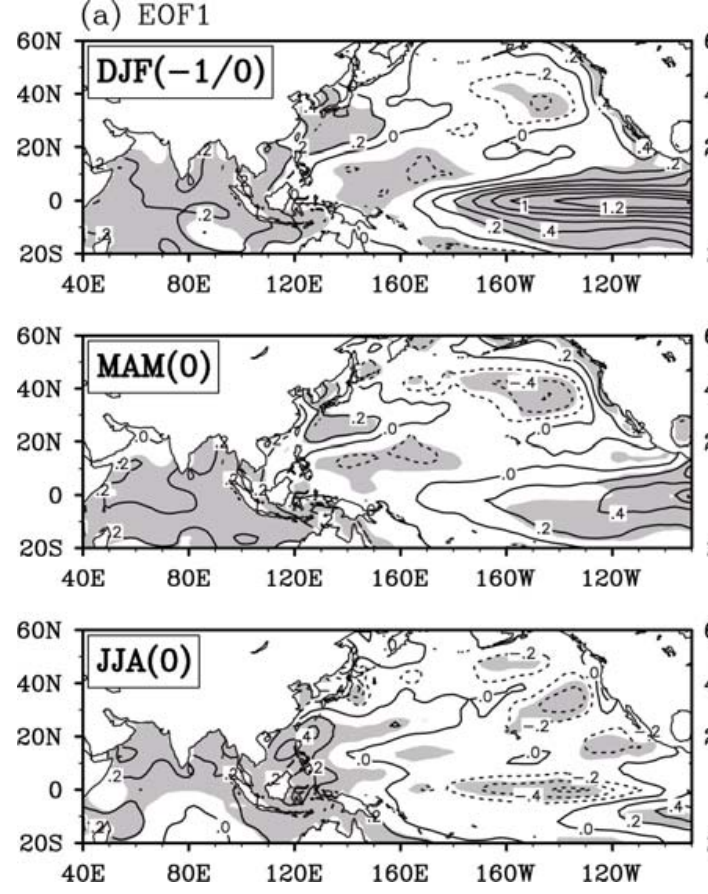

(b) EOF2
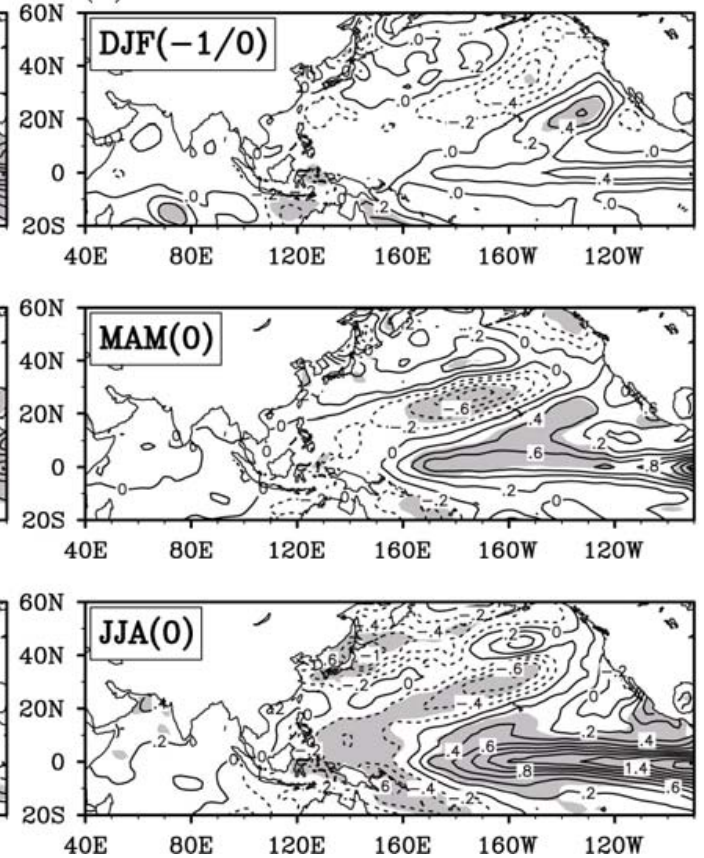

Fig. 3. Evolution of SST anomalies associated with the two MV-EOF modes. These patterns were obtained by regressing with respect to the first two principal components of the MV-EOF analysis for three consecutive seasons: DJF(-1/0), MAM(0) and JJA(0), where " 0 " denotes the year concurring with the EA-WNP leading modes. "-1" denotes the year precedes year 0. Grey shadings indicate areas where the anomalies are statistically significant at the $95 \%$ confidence level. The SST data are from NOAA Extended Reconstructed Sea Surface Temperature Version 2.

conditions except 1990 . Thus, the second mode is primarily associated with developing El Nino and La Nina events.

\section{The origins and teleconnection of the two major modes}

The results in Sect. 3 have hinted the linkage between the two major modes and ENSO. In order to further clarify the origins of these two modes, we investigate their linkages with the lower boundary forcing, especially the SST anomalies associated with the first two MV-EOF modes in entire IndoPacific ocean, and their teleconnection with northern hemisphere circulation anomalies. The latter may reveal source of the variability in the extratropics.

4.1 The anomalous SST forcing associated with the major modes

Figure 3a shows the seasonal evolution of SST anomalies that are regressed with respect to the principal component of the leading mode. The EASM anomaly shown in Fig. 2a is preceded by a rapid decay of a mature El Nino from the previous winter to the concurrent spring, confirming that the leading mode occurs in an El Nino decay year. By the concurrent summer, however, the eastern Pacific SST becomes a nearly neutral state. Thus, the anomalous EASM cannot be directly attributed to the remote forcing from the eastern Pacific.

Then, how can an El Nino event that matures in the previous winter have a "delayed" influence on EASM? It turns out that the enhanced subtropical frontal rainfall in the summer after the mature phase of a strong El Nino (Fig. 2a) is induced by the abnormal WNP anticyclone. This anticyclone is established in the fall of the El Nino developing year (Wang and Zhang, 2002) and develops during the mature phase of El Nino. After the mature phase the anomalous WNP anticyclone is maintained by a positive feedback between the anticyclone and the underlying SST cooling to the east of the anticyclone (Wang et al., 2000). This positive feedback works as follows. The SST cooling to the east of the anticyclone suppresses local convection, thereby stimulating descending atmospheric Rossby waves which enhance the WNP anticyclone in their westward journey; on the other hand, the enhanced anomalous WNP anticyclone further cools the sea surface to its east, because the basic state winds are northeasterly trades and the anomalous northeasterly (to the east of the anomalous anticyclone) increases the total wind speed, thereby enhancing evaporation and entrainment cooling.

One important feature of SST anomalies associated with EOF1 shown in Fig. 3a is the developing positive SST anomalies in the tropical Indian Ocean and over Maritime continents. What is the role of these SST anomalies for 


\section{(a) EOF1}

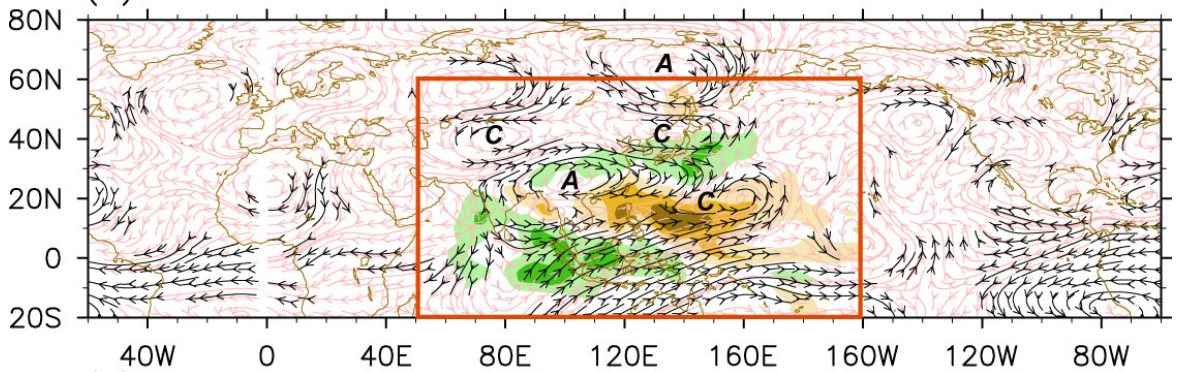

(b) EOF2

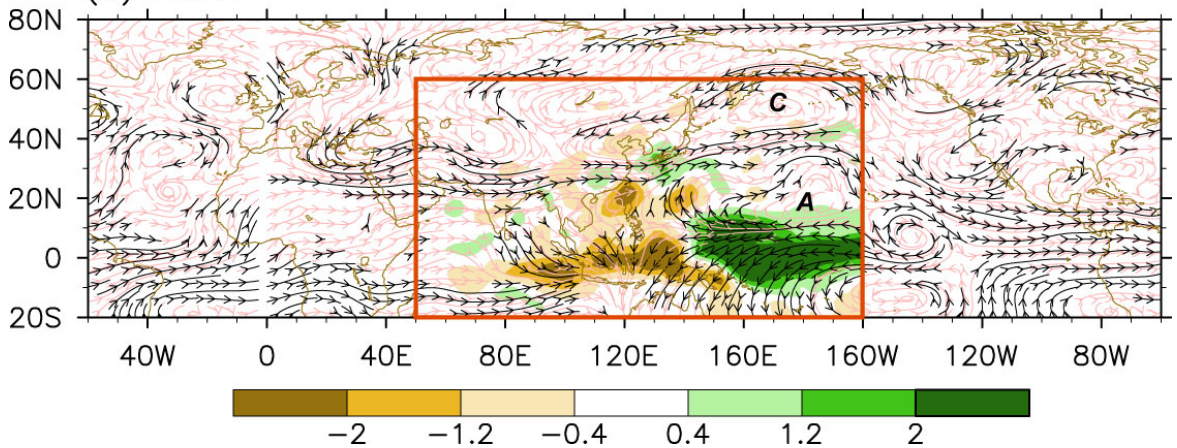

Fig. 4. Teleconnection patterns associated with the first two MV-EOF modes of interannual variability. Shown are the JJA precipitation anomalies (color shading in units of $\mathrm{mm} /$ day) and $200 \mathrm{hpa}$ anomalous streamlines (pink lines) over the North Hemisphere. The anomalies were obtained by regression with respect to the first two principle components, respectively. The dark streamlines are statistically significant at the $95 \%$ confidence level.

the formation of anomalous WNP anticyclone? The Indian Ocean and Maritime continent (MC) warming during and after the mature phase of El Nino is a delayed response to remote El Nino forcing through "atmospheric bridge". These anomalies are located to the west and southwest of the WNP anticyclone. In theory, such anomalies may affect the atmospheric circulation in situ or to the west of these SST anomalies. Thus, these SST anomalies should not have a major impact on the WNP anticyclone. However, the MC warming may draw anomalous easterly along the equator in the western Pacific, which could reinforce the southern flank of the WNP anticyclone.

Figure $3 \mathrm{~b}$ shows the evolution of the SST anomalies associated with the second mode. The EASM anomaly shown in Fig. $2 b$ is preceded by positive SST anomalies in the previous March-April-May, indicating an early development of El Nino in the eastern Pacific. A pattern with reversed polarities in Fig. 2b corresponds to a La Nina development stage. Thus, ENSO provides a direct forcing for the second mode.

\subsection{The teleconnection associated with the major modes of variability}

The precipitation anomalies represent anomalous latent heat sources/sinks and they are instrumental in understanding of tropical-extratropical teleconnection. Figure 4 shows the anomalous precipitation in Asian monsoon region and the
$200 \mathrm{hPa}$ streamfunction in the northern hemisphere associated with the first two major modes.

The precipitation anomalies associated with the leading mode are characterized by a meridional sandwich pattern with enhanced convection in the western Maritime Continent, suppressed convection over the WNP monsoon trough (ITCZ), and enhanced Meiyu/Changma/Baiu. This pattern means that an equatorial enhancement of the western Maritime continental convection may weaken the WNP ITCZ while strengthen EA subtropical frontal precipitation. This is a mechanism by which ENSO-induced anomalous Walker cell can influence EASM. During a La Nina, for instance, the eastern Pacific is colder than normal, which induces an anomalous Walker cell that is sinking in the eastern $\mathrm{Pa}$ cific while rising over the MC. In this case, the convection and rainfall over the $\mathrm{MC}$ are enhanced. The enhanced MC rainfall will affect East Asia by setting up an anomalous meridional (Hadley type) cell, which normally takes a sandwich pattern as shown by the leading mode (wet maritime continent, dry WNP monsoon trough, and wet East Asian subtropical front). Corresponding to such an anomalous precipitation pattern, the $200 \mathrm{hPa}$ streamfunction shows a prominent south-north oriented wave train emanating from the deep tropics to polar region in the EA-WNP sector between $70^{\circ} \mathrm{E}$ and $160^{\circ} \mathrm{E}$ (Fig. 4a). This pattern resembles the Pacific-Japan pattern previously noted by Nitta (1987) and Huang and Wu (1989). Note that this north-south 

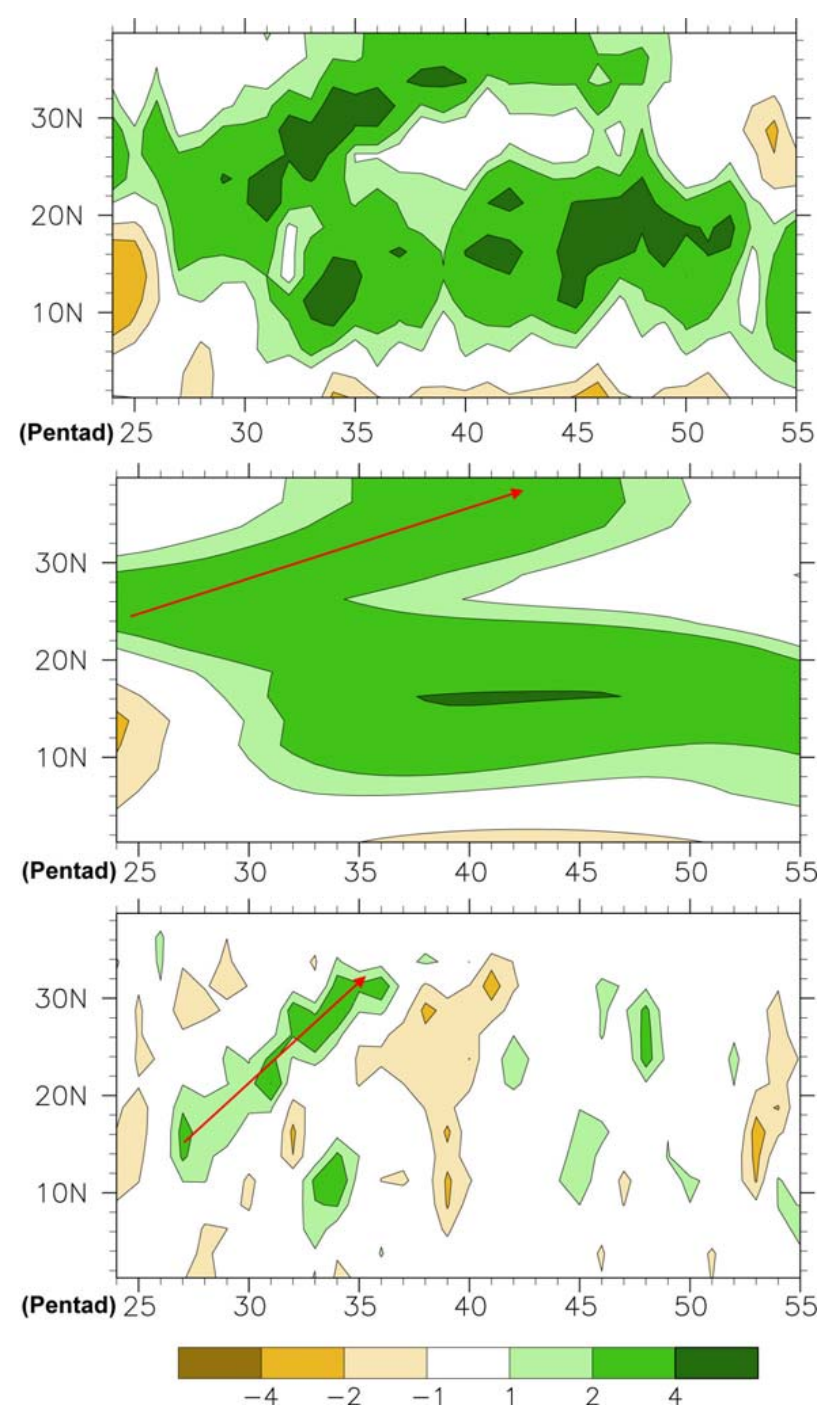

Fig. 5. The upper panel shows climatological pentad mean annual cycle of precipitation (contour interval is $\mathrm{mm} /$ day) as a function of latitude (ordinate) and Julian pentad (abscissa). The middle and lower panels are the same as in the upper panel except for the slow and fast annual cycle, respectively. The definitions of the slow and fast annual cycle are referred to the text. The red arrows indicate the seasonal migration of the subtropical rain band as seen in the slow and fast annual cycles.

teleconnection shows a meridional wavenumber-two structure from the equator to North Pole. In view of its great meridional extent, we may refer it to as tropical-polar teleconnection. Over the equator, $200 \mathrm{hPa}$ wind anomalies feature a zonal wavenumber-one pattern with westerly over the Asian-Australian sector and easterlies elsewhere.

The precipitation anomalies associated with the second mode is dominated by an equatorial east-west dipole with suppressed rainfall over the Maritime Continent and enhanced convection in the equatorial western Pacific (Fig. 4b).
This pattern resembles the rainfall pattern associated with a shift of normal Walker cell during a developing El Nino. The rainfall anomaly over the EA-WNP sector exhibits a regional north-south dipole with a dry anomaly near Philippines and a wet anomaly over the Southern Japan. The teleconnection associated with the second mode shows also a pronounced tropical-polar pattern but the position is in between $110^{\circ} \mathrm{E}$ and $160^{\circ} \mathrm{W}$. In conjunction with this tropical-polar teleconnection is a discernible "great circle" wave train pattern that resembles a westward-shifted Pacific-North America (PNA) teleconnection pattern during northern winter (Wallace and Gutzler, 1981).

The aforementioned teleconnection patterns are likely forced by tropical precipitation anomalies as evidenced by their baroclinic structures south of $25^{\circ} \mathrm{N}$. For instance, in Fig. 4a the dry anomaly (anomalous cooling) over the Philippine Sea stimulates a low-level anticyclonic anomaly and an upper-level cyclonic anomaly. Similarly, the $200 \mathrm{hPa}$ anticyclonic anomaly over the western-central Pacific in Fig. 4b results from an equatorial Rossby wave response to the equatorial heating centered around $160^{\circ} \mathrm{E}$. The structure poleward $25^{\circ} \mathrm{N}$ becomes more equivalent barotropic, but, as noted by Kosaka and Nakamura (2006), there is a subtle poleward tilt with height. The results here suggest that the first two modes of the interannual variability of the EASM are unlikely related to extratropical forcing.

\section{Annual march of the EASM precipitation}

Figure 5 shows the climatological seasonal march of the pentad mean GPCP precipitation averaged between $110^{\circ} \mathrm{E}$ and $125^{\circ} \mathrm{E}$. During boreal summer, the total annual cycle (top panel) shows that ITCZ is located between $10^{\circ} \mathrm{N}$ and $20^{\circ} \mathrm{N}$ and the EA subtropical rain band is located between $20^{\circ} \mathrm{N}$ and $40^{\circ} \mathrm{N}$. The two bands join together from mid-May to early June during the onset of the South China Sea summer monsoon at pentad 28 and the establishment of the EA subtropical frontal rain band. The relative dry zone in between the two rain bands reflects the dry climate under the influence of the WNPSH.

The total annual cycle may be decomposed to two components (modes): a slow and a fast annual cycle (LinHo and Wang, 2002). The slow annual cycle is defined by the first three harmonics of the climatological pentad mean time series (the annual, semiannual, and 120-day harmonics). The fast annual cycle contains the 4th to 12th harmonics and represents the climatological intraseasonal oscillation (CISO) (Wang and Xu, 1997). The slow and fast annual cycles are presented in the middle and lower panel, respectively, on Fig. 5.

For the ITCZ, its peak on slow annual cycle occurs in the late July (around Pentad 40), while its CISO has two major wet phases, one in the late June (Pentad 35) and the other in the late August (Pentad 47). The former corresponds to 

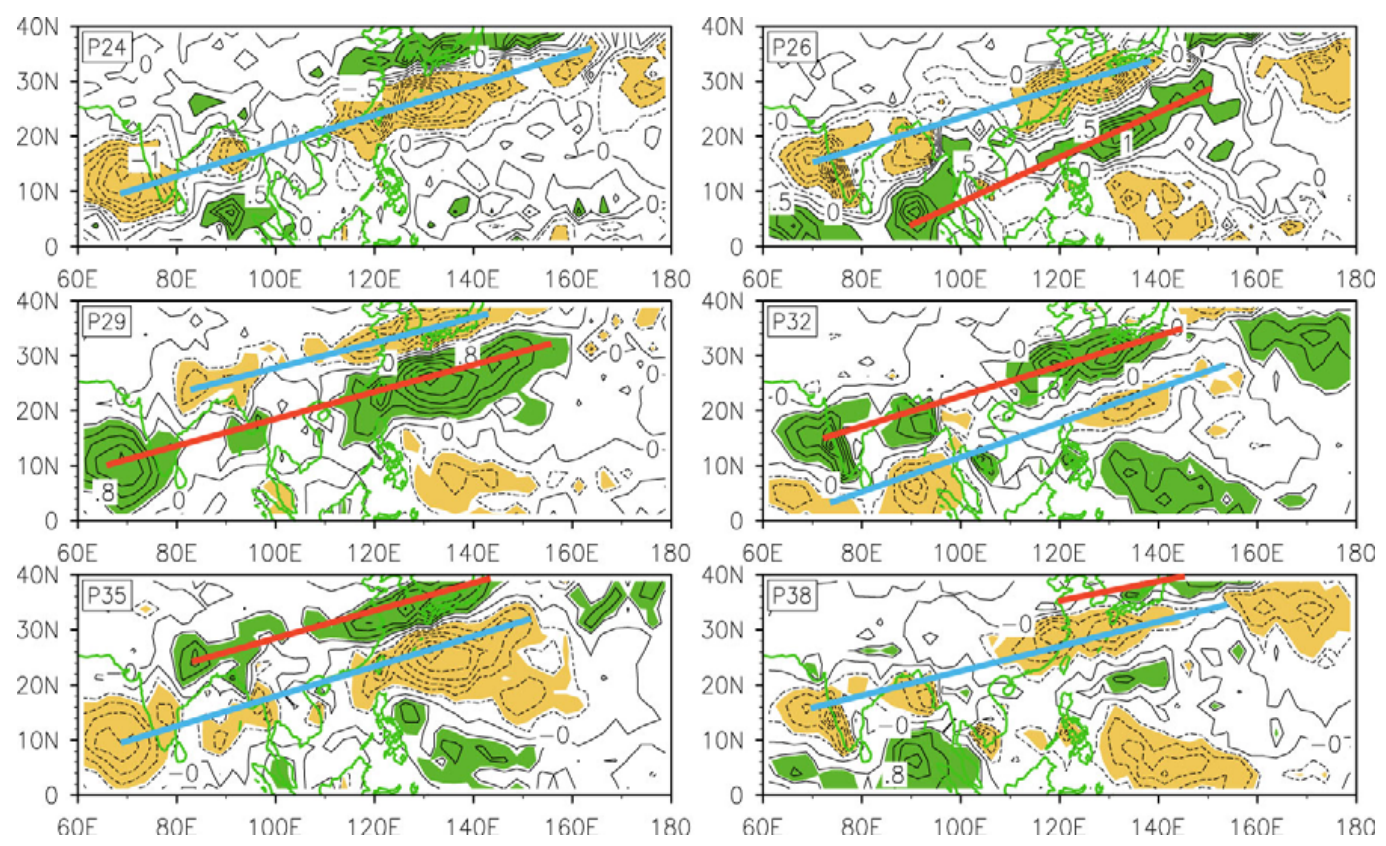

Fig. 6. A consequence of maps at different times (pentad) of the year showing the seasonal migration of the precipitation band (in unit of $\mathrm{mm} /$ day) of the climatological intraseasonal oscillation (or fast annual cycle component). The blue and red lines indicate the anomalous dry and wet zones. Color Shadings are above 95\% confidence level. Precipitation was derived from GPCP pentad mean data.

the peak Meiyu or Baiu and the latter reflects the influence of Typhoon during its peak season. For the EA subtropical precipitation band, the seasonal march is best depicted by the fast annual cycle or the CISO component. Figure 6 indicates that the subtropical rain band advances northward from the northern South China Sea $\left(10^{\circ} \mathrm{N}-22^{\circ} \mathrm{N}\right)$ in the mid-May to the northern China toward the end of July, taking about two months. This northward advance exemplifies a response to the seasonal march of solar radiation forcing with a onemonth phase delay due to the thermal inertia of the coupled atmosphere-land-ocean system.

Note that the seasonal advance of the EA subtropical frontal rain band is a part of a continental-scale seasonal march of a southwest-northeastward tilted rain band over the entire Asian monsoon rainy domain. This can be clearly seen from Fig. 6 where the CISO component is presented for the period from 16 May to 25 July. On 16 May when the South China Sea rainy season starts, an elongated anomalous dry zone is seen to the north of the South China Sea from India to southern China, indicating that a pre-summer monsoon dry weather leads the onset of the South China Sea monsoon. By 26 May, the EA summer monsoon rain band is well established, extending from the northern South China Sea to the WNP with its northern edge reaching Taiwan and Okinawa; meanwhile monsoon rains approach the southern tip of Indian subcontinent. Around 10 June, a fully developed CISO rain band is seen across southern India, northern Bay of Bengal, southern China to Okinawa, indicating burst of heavy rains in these regions. At this stage, the northern edge of the rain band reaches the Yangtze River and southern Japan, thus, the Meiyu and Baiu start. By 25 June, the rain band moves further north and the Meiyu and Baiu reach their peak phases. In the subsequent month (see 10 July and 25 July), the rain band moves further north in the EA sector and starts the rainy season in the northern and northeast China. In summary, the systematic northwestward advance of the Asian summer monsoon rain band manifests itself as a response to the annual solar forcing.

On the annual time scale, it is seen that the ITCZ and EA subtropical rain bands reaches their maximum nearly the same time in the late July, suggesting that an in-phase relationship between the ITCZ and EA subtropical precipitation on the annual time scale due to the coordination of the same solar radiative forcing. The results in Figs. 5 and 6 also indicate that on the annual time scale, the strength of the EASM can be represented by the northernmost position of the rain band or the precipitation in the central North China.

\section{Discussion}

6.1 The relationship between the ITCZ and EA subtropical frontal precipitation

On the interannual time scale the amounts of precipitation in the ITCZ and the EA subtropical frontal region are anticorrelated. From this modern meteorological point of view, the strengthening of the subtropical EASM may not be interpreted as a result of enhancement and northward advance 
of the WNP ITCZ. However, one has to be cautious about this inference, because the mechanism driving EASM interannual variability fundamentally differs from those that operate on the orbital time scale.

The result in Sect. 3 indicates that the first two modes of interannual variations are primarily caused by internal feedback processes: the interaction of the atmosphere and ocean in the eastern Pacific cold tongue region and the interaction between the Asian monsoon and the warm pool ocean. That is to say, the EASM variability is essentially caused by internal feedback processes within the coupled climate system. However, on the orbital time scale, the monsoon variability is driven by solar radiative forcing external to the climate system. To some extent, the mechanism responsible for paleomonsoon variability on orbital time scale is similar to that governing the annual variation because the annual variation and the orbital variation share the same primary driver, i.e., the land-sea thermal contrast and its response to the change of solar forcing. As seen from Fig. 5, on the annual time scale the solar forcing generates an in-phase relationship between the response of the subtropical monsoon and ITCZ, implying that for the forced mode the advance of the ITCZ may be in phase with enhanced EA subtropical precipitation.

\subsection{Measure of the intensity of the EASM}

One of the major characteristics of the internal modes is the inhomogeneity in the precipitation variation over the subtropical EA, in particular, the out-of-phase relationship between the Maiyu/Baiu and the precipitation in the northern China. The leading mode of the interannual variability suggests the significance of the Meiyu/Baiu/Changma in gauging the strength of the EASM. But, in modern meteorology, the traditional meaning of a strong EASM implies strong precipitation in northern China that corresponds to a deficient Meiyu. This is apparently inadequate in terms of leading mode of variability and therefore this definition should be reversed so that an abundant Meiyu/Baiu should be called a strong EASM (Wang et al., 2008).

The annual variation of precipitation, on the other hand, is controlled by seasonal march. Figure 6 shows that the advance of the rainy season, which starts from $20^{\circ} \mathrm{N}$ in mid-May to $40^{\circ} \mathrm{N}$ in mid-July, is the most spectacular phenomenon on the Earth. This unique phenomenon has drawn enormous attention since the classic work of Tu (1944) (Guo and Wang 1981; Tao and Chen, 1987; Ding, 1994; Wang and LinHo, 2002). From the point of view of seasonal march, the rainy season in northern China is a logical indication of the monsoon intensity. Also of importance is that under the solar forcing the position of the northern edge of the summer monsoon or the precipitation in northern China may represent the intensity change in a large area of the subtropical EA. In the mountain lift experiment, for instance, the uplift of Tibetan Plateau appears to extend the EASM domain poleward (Kitoh, 2002; Wu et al., 2005). In that case, an alternative index which describes the northward advance of the monsoon climate is relevant. On the orbital time scale, the northern edge of the southerly monsoon responds to the solar forcing, thus focusing on the intensity of northern China precipitation would reflect the EASM strength well.

The inferences and hypothesis proposed in the present analysis of the modern record should be verified by proxy records across the EASM sector including both the land and ocean and both the mid-latitude and the tropics. They should also be tested by examination of paleoclimate simulations, which are valuable for revealing the structure and the cause of the EASM variability on the millennium and orbital time scales. The latter is under investigation.

Acknowledgements. Jian Liu and Bin Wang acknowledge supports received from the Innovation Project of Chinese Academy of Sciences (Grant Nos. KZCX2-YW-315 and KZCX2-YW-319) and the National Natural Science Foundation of China (Grant Nos. 40672210 and 40871007). Bin Wang and Jing Yang acknowledge support from IPRC which is in part sponsored by JAMSTEC. Jing Yang is also supported by the National Natural Science Foundation of China (Grant No. 40221503).

Edited by: P. Braconnot

\section{References}

Adler, R. F., Huffman, G. J., Chang, A., Ferraro, R., Xie, P., Janowiak, J., Rudolf, B., Schneider, U., Curtis, S., Bolvin, D., Gruber, A., Susskind, J., and Arkin, P.: The Version 2 Global Precipitation Climatology Project (GPCP) Monthly Precipitation Analysis (1979-Present), J. Hydrometeorol., 4, 1147-1167, 2003.

An, Z. S.: The history and variability of the East Asian paleomonsoon climate, Quaternary Sci. Rev., 19(1-5), 171-187, 2000.

Ding, Y. H.: Monsoons Over China, Springer, New York, 419 pp., 1994.

Ding, Y. H.: Summer monsoon rainfalls in China, J. Meteorol. Soc. Jpn., 70(1B), 373-396, 1992.

Ding, Z. L., Liu, T. S., Rutter, N. W., Yu, Z. W., Guo, Z. T., and Zhu, R. X.: Ice-volume forcing of East-Asian winter monsoon variations in the past 800,000 years, Quaternary Res., 44(2), 149-159, 1995.

Guo, Q. Y. and Wang, J. Q.: Interannual variations of rain spell during predominant summer monsoon over China for recent thirty years, Acta Geogr. Sin., 36, 187-195, 1981 (in Chinese).

Huang, R. H. and Wu, Y. F.: The influence of ENSO on the summer climate change in China and its mechanism, Adv. Atmos. Sci., 6 , 21-32, 1989.

Kanamitsu, M., Ebisuzaki, W., Woollen, J., Yang, S. K., Hnilo, J. J., Fiorino, M., and Potter, G. L.: NCEP-DOE AMIP-II reanalysis (R-2), B Am. Meteorol. Soc., 83(11), 1631-1643, 2002.

Kitoh, A.: Effects of large-scale mountains on surface climate a coupled ocean-atmosphere general circulation model study, J. Meteorol. Soc. Jpn., 80, 1165-1181, 2002.

Kosaka, Y. and Nakamura, H.: Structure and dynamics of the summertime pacific-Japan teleconnection pattern, Q. J. Roy. Meteor. Soc., 132, 2009-2030, 2006. 
Lee, E. J., Jhun, J. G., and Park, C. K.: Remote connection of the northeast Asian summer rainfall revealed by a newly defined monsoon index, J. Climate, 18, 4381-4393, 2005.

LinHo and Wang, B.: The time-space structure of the Asian-Pacific summer monsoon: A fast annual cycle view, J. Climate, 15, 2001-2019, 2002.

Murakami, T. and Matsumoto, J.: Summer monsoon over the Asian continent and western north Pacific, J. Meteorol. Soc. Jpn., 72(5), 719-745, 1994.

Nitta, T.: Convective activities in the tropical western Pacific and their impact on the Northern-Hemisphere summer circulation, J. Meteorol. Soc. Jpn., 65(3), 373-390, 1987.

North, G. R., Bell, T. L., Cahalan, R. F., and Moeng, F. J.: Sampling errors in the estimation of empirical orthogonal functions, Mon. Weather Rev., 110(7), 699-706, 1982.

Smith, T. M. and Reynolds, R. W.: Improved extended reconstruction of SST (1854-1997), J. Climate, 17(12), 2466-2477, 2004.

Tao, S. Y. and Chen, L.: A review of recent research on East Asian summer monsoon in China, in: Monsoon Meterology, edited by: Chang, C. P. and Krishnamurti, T. N., Oxford University Press, London, 60-92, 1987.

Tu, C. W. and Huang, S. S.: The advance and withdrawal of Chinese summer monsoon, Acta Meteor. Sin., 18, 81-92, 1944 (in Chinese).

Wallace, J. M. and Gutzler, D. S.: Teleconnections in the geopotential height field during the northern Hemisphere winter, Mon. Weather Rev., 109(4), 784-812, 1981.

Wang, B. and LinHo: Rainy season of the Asian-Pacific summer monsoon, J. Climate, 15(4), 386-398, 2002.

Wang, B. and Xu, X.: Northern Hemisphere summer monsoon singularities and climatological intraseasonal oscillation, J. Climate, 10, 1071-1085, 1997.

Wang, B. and Zhang, Q.: Pacific-East Asian teleconnection, part II: How the Philippine Sea anticyclone established during development of El Nino, J. Climate, 15, 3252-3265, 2002.
Wang, B., Wu, R. G., and Fu, X. H.: Pacific-East Asian teleconnection: how does ENSO affect East Asian climate?, J. Climate, 13(9), 1517-1536, 2000.

Wang, B., Wu, Z. W., Li, J. P., Liu, J., Chang, C. P., Ding, Y. H., and Wu, G. X.: How to Measure the Strength of the East Asian Summer Monsoon?, J. Climate, 21, 4449-4463, doi:10.1175/2008JCLI2183.1, 2008.

Wang, B.: The vertical structure and development of the ENSO anomaly mode during 1979-1989, J. Atmos. Sci., 49(8), 698712, 1992.

Wang, Y. J., Cheng, H., Edwards, R. L., An, Z. S., Wu, J. Y., Shen, C. C., and Dorale, J. A.: A high-resolution absolute-dated Late Pleistocene monsoon record from Hulu Cave, China, Science, 294(5550), 2345-2348, 2001.

Wu, G. X., Liu, Y. M., Liu, X., Duan, A. M., and Liang, X. Y.: How the heating over the TP affects the Asian climate in Summer, Chin., J. Atmos. Sci., 29, 47-56, 2005.

$\mathrm{Wu}, \mathrm{R}$. G. and Wang, B.: Interannual variability of summer monsoon onset over the western North Pacific and the underlying processes, J. Climate, 13(14), 2483-2501, 2000.

Yancheva, G., Nowaczyk, N. R., Mingram, J., Dulski, P., Schettler, G., Negendank, J. F., W., Liu, J. Q., Sigman, D. M., Peterson, L. C., and Haug, G. H.: Influence of the intertropical convergence zone on the East Asian monsoon, Nature, 445(7123), 7477, 2007.

Zhang, R. H., Sumi, A., and Kimoto, M.: Impact of El Nino on the East Asian monsoon: A diagnostic study of the '86/87 and '91/92 events, J. Meteorol. Soc. Jpn., 74(1), 49-62, 1996.

Zhou, T. J. and Yu, R. C.: Atmospheric water vapor transport associated with typical anomalous summer rainfall patterns in China, J. Geophys. Res., 110, D08104, doi:10.1029/2004JD005413, 2005.

Zhu, Q. G., He, J. H., and Wang, P. X.: A study of circulation differences between east-Asian and Indian summer monsoons with their interaction, Adv. Atmos. Sci., 3(4), 466-477, 1986. 